\title{
A new species of Hypoprepia from the mountains of central Arizona (Lepidoptera, Erebidae, Arctiinae, Lithosiini)
}

\author{
John Douglas Palting, ${ }^{1,3}$, Douglas C. Ferguson ${ }^{2, \dagger}$, Wendy Moore ${ }^{3}$ \\ I Graduate Interdisciplinary Program in Entomology and Insect Science, University of Arizona, Tucson, Ari- \\ zona, 85721-0036, USA 2 Systematic Entomology Laboratory, PSI, Agricultural Research Service, U.S. De- \\ partment of Agriculture, clo Smithsonian Institution, Washington, D.C., 20013-7012, USA 3 Department of \\ Entomology, University of Arizona, Forbes 410, Tucson, Arizona, 85721-0036, USA \\ Corresponding author: John Douglas Palting (john.palting@roche.com)
}

Academic editor: C. Schmidt | Received 22 May 2018 | Accepted 9 July 2018 | Published 8 October 2018

http://zoobank.org/74A259E0-93C3-492E-AC23-4095830CO2EE

Citation: Palting JD, Ferguson DC, Moore W (2018) A new species of Hypoprepia from the mountains of central Arizona (Lepidoptera, Erebidae, Arctiinae, Lithosiini). In: Schmidt BC, Lafontaine JD (Eds) Contributions to the systematics of New World macro-moths VII. ZooKeys 788: 19-38. https://doi.org/10.3897/zookeys.788.26885

\begin{abstract}
A new firefly-mimicking lichen moth of the genus Hypoprepia, H. lampyroides Palting \& Ferguson, sp. n., is described from the mountains of east-central Arizona and the Sierra Madre Occidental of Mexico. Hypoprepia Hübner, 1831 is a North American genus of lithosiine tiger moths, previously consisting of five species: $H$. fucosa Hübner, 1831 and $H$. miniata (Kirby, 1837), both of eastern and central North America; H. cadaverosa Strecker, 1878 from the Rocky Mountains into New Mexico and west Texas; $H$. inculta $\mathrm{H}$. Edwards, 1882, a widespread western USA species and H. muelleri Dyar, 1907 from the vicinity of Mexico City. The latter is herein synonymized under $H$. inculta (= H. muelleri syn. n.), resulting in the total number of taxa in the genus unchanged at five.
\end{abstract}

\section{Keywords}

Lithosiini, Madrean fauna, mimicry, Sky Islands

Copyright John Douglas Palting et al. This is an open access article distributed under the terms of the Creative Commons Attribution License (CC BY 4.0), which permits unrestricted use, distribution, and reproduction in any medium, provided the original author and source are credited. 


\section{Introduction}

The mountains of southeastern Arizona and northeastern Sonora are well known as a biological blending zone between the fauna of the Rocky Mountains to the north and Mexico's Sierra Madre Occidental to the south. Positioned between these two great mountain ranges, the Sky Island Region contains a series of smaller mountain ranges that have oak and pine at higher elevations, each range being separated from one another by expanses of drier grasslands and desert. Sky Island ranges often harbor relict populations of plants and animals that suggest that in the distant past, both geology and climate allowed connections between the flora and fauna of the Rockies and the Sierra Madre (Warshall 1995). Examples among Lepidoptera of this connection include Chiricahua multidentata (Guedet, 1941) and Chiricahua lichenaria Ferris, 2010 (Geometridae, Ennominae), known in the US only from the highest elevations of the Chiricahua Mountains in SE Arizona, with the next nearest recorded population being in El Salto, Durango, nearly 900 miles to the south. A similarly striking disjunct population occurs with Nemoria splendidaria (Grossbeck, 1910) (Geometridae, Geometrinae) known only from the top of the Huachuca Mountains, Arizona in the US with the nearest Mexico records also being from Durango. Alexicles aspersa Grote, 1883 (Erebidae, Arctiinae) occurs sporadically from Colorado to several places in the White Mountains of central Arizona, adjacent parts of New Mexico, and not again until the top of the Sierra Madre in the vicinity of Yecora, Sonora, Mexico, skipping the Sky Island ranges entirely. Other rare US Lepidoptera that exhibit similar but less dramatically disjunct distributions include the lasiocampids Caloecia entima Franclemont, 1973 and C. juvenalis (Barnes \& McDunnough, 1911) (Lasiocampidae, Lasiocampinae), C. entima known in the US only from the high elevations of the Chiricahuas, and C. juvenalis only from the Chiricahuas and Huachucas, with spotty distributions in the Mexican state of Sonora (Sierra Mariquita, Sierra del Tigre and Yecora). Agylla septentrionalis Barnes \& McDunnough, 1911 (Erebidae, Arctiinae, Lithosiini) is also known from isolated high-elevation populations in the Chiricahua and Huachuca Mountains, separated from the nearest Sierra Madre populations in Yecora, Sonora by 400 miles. These are just a few of many examples among Lepidoptera species with relict disjunct distributions indicating an historical Rocky Mountain-Madrean connection in this region.

We can now add another rare species of Lepidoptera from Arizona to the body of evidence supporting this past faunal connectivity. The moth was first noticed by the late Ron Leuschner, who collected a specimen on the door of a rental cabin in the hamlet of Greer, White Mountains, Arizona in 1988. Leuschner sent this specimen to Ferguson, who, prior to his death in 2002, recognized it as new and started to describe it based upon this specimen and two additional specimens he located in collections. Ferguson had dissected and made some comments on the male genitalia, but had not examined the internal structures of the female.

In June 2017, JDP and Ray Nagle had the good fortune of collecting more than 30 specimens of this new species along Highway 191 in the vicinity of Rose Peak, Blue Ridge Primitive Area, Greenlee County, Arizona. Flying sympatrically with Hypopre- 
pia inculta Edwards, 1882 was the similar-looking, but much larger bodied and more boldly colored, $H$. inculta look-alike (Figs $1-5$ ). Finally, here was the almost mythical moth that Leuschner had found nearly 30 years prior in Greer. Its similarity to $H$. inculta (Figure 6), combined with narrow endemicity and an early flight period just prior to or at the onset of the summer rains, may account for the paucity of records of this new species. It appears to fly throughout the night, with new individuals showing up on the sheet with regularity until dawn, outnumbered by $H$. inculta by approximately $4: 1$. Most of the specimens collected were males, but two females of the new species were collected and kept alive for ova, allowing for the larvae to be reared and photographed for the first time.

Other noteworthy species flying alongside the Hypoprepia were Nadata gibbosa (JE Smith, 1797) (Notodontidae, Phalerinae) and Spilosoma virginica (Fabricius, 1798) (Erebidae, Arctiinae, Arctiini), both common northern and eastern species, but at the extreme southern limit of their ranges here, as well as Apantesis f-pallida (Strecker, 1878) (Erebidae, Arctiinae, Arctiini), a primarily Rocky Mountain species, very rare this far southwest. Also present was the strikingly beautiful Erastria viridiruferia (Neumoegen, 1881) (Geometridae, Ennominae), another Madrean species that occurs in central Arizona, with sporadic records from the Sky Islands Region through the Sierra Madre proper, where it occurs regularly at mid to high elevations.

\section{Methods and materials}

\section{Phylogenetic analysis}

Total genomic DNA was extracted from the right middle leg of each voucher specimen using the Qiagen DNeasy Blood and Tissue Kit (Qiagen, Valencia, CA), according to manufacturer suggested protocol. The barcoding region of the mitochondrial gene cytochrome oxidase subunit 1 (COI) was PCR amplified with primers LCO1490 and HCO2198 (Hebert et al. 2003). PCR products were cleaned, quantified, normalized, and sequenced in both directions at the University of Arizona's Genomic and Technology Core Facility using a 3730 or 3730XL Applied Biosystems automatic sequencer. Chromatograms were assembled and initial base calls were made for each gene with Phred (Green and Ewing 2002) and Phrap (Green 1999) as orchestrated by Mesquite Ver. 3.4 (Maddison and Maddison 2018) and Chromaseq vers. 1.3 (Maddison and Maddison 2017). Final base calls were made in Mesquite and ambiguous bases were designated by a standard ambiguity code. Resulting sequences were deposited in GenBank (Table 1). Previously published COI sequences of Hypoprepia and all other members of the tribe Lithosiini were downloaded from GenBank and the Barcode of Life Database (Table 1). All 500 sequences were assembled into a single matrix and were aligned using MAFFT vers. 7 (Katoh and Standley 2013). The aligned matrix was partitioned by codon position, with each codon position allowed to have independent parameter values for the model of evolution. Maximum likelihood (ML) 
Table I. GenBank/BOLD accession number of the species.

\begin{tabular}{|c|c|}
\hline Species name & GenBank/BOLD Accession Number \\
\hline \multicolumn{2}{|l|}{ Outgroup } \\
\hline Abrochocis esperanza & KC571047.1 \\
\hline Balbura dorsisigna & KC571053.1 \\
\hline Balbura intervenata & KC571052.1 \\
\hline Chrysochlorosia magnifica & KC571057.1 \\
\hline Cisthene angelus & BBLOE1648-12 \\
\hline Cisthene barnesii & ABLCW009-10 \\
\hline Cisthene barnesii & LMEM919-09 \\
\hline Cisthene barnesii & RDNMF900-08 \\
\hline Cisthene deserta & ABLCW126-10 \\
\hline Cisthene dorsimacula & RDNMF903-08 \\
\hline Cisthene faustinula & LOCBC003-06 \\
\hline Cisthene juanita & IAWL658-09 \\
\hline Cisthene kentuckiensis & HKONS224-08 \\
\hline Cisthene liberomacula & LOCBC697-06 \\
\hline Cisthene martini & LMEM065-09 \\
\hline Cisthene packardii & LSUSA097-06 \\
\hline Cisthene perrosea & ABLCW128-10 \\
\hline Cisthene picta & LPOKA060-08 \\
\hline Cisthene plumbea & KC571059.1 \\
\hline Cisthene polyzona & BLPDD935-09 \\
\hline Cisthene sp. & LPYPC028-08 \\
\hline Cisthene sp. & LPYPC119-08 \\
\hline Cisthene subjecta & HKONS229-08 \\
\hline Cisthene subrufa & LPYPB681-08 \\
\hline Cisthene subrufa & LPYPC078-08 \\
\hline Cisthene tenuifascia & BBLSW086-09 \\
\hline Cisthene unifascia & ABLCW140-10 \\
\hline Dolichesia falsimonia & KC571062.1 \\
\hline Gardinia anopla & KC571075.1 \\
\hline Lycomorphodes correbioides & KC571088.1 \\
\hline Lycomorphodes sordida & KC571089.1 \\
\hline Talara cara & KC571098.1 \\
\hline Talara lepida & KC571099.1 \\
\hline Talara nr. mona & KC571100.1 \\
\hline \multicolumn{2}{|l|}{ Ingroup } \\
\hline Hypoprepia cadaverosa & KC571080.1 \\
\hline Hypoprepia cadaverosa & MF922743.1 \\
\hline Hypoprepia cadaverosa & MF923063.1 \\
\hline Hypoprepia cadaverosa & MF923535.1 \\
\hline Hypoprepia cadaverosa & MF923758.1 \\
\hline
\end{tabular}




\begin{tabular}{|c|c|}
\hline Species name & GenBank/BOLD Accession Number \\
\hline Hypoprepia cadaverosa & MF923893.1 \\
\hline Hypoprepia cadaverosa & MF924076.1 \\
\hline Hypoprepia fucosa & MF923771.1 \\
\hline Hypoprepia fucosa & MF924037.1 \\
\hline Hypoprepia fucosa & KC571078.1 \\
\hline Hypoprepia fucosa tricolor & KC571079.1 \\
\hline Hypoprepia inculta & ABLCW242-10 \\
\hline Hypoprepia inculta & CMAZA783-10 \\
\hline Hypoprepia inculta 4170 & MH337839 \\
\hline Hypoprepia inculta & RDNMG037-08 \\
\hline Hypoprepia inculta 3259 & MH337840 \\
\hline Hypoprepia inculta & ABLCW240-10 \\
\hline Hypoprepia inculta & ABLCW241-10 \\
\hline Hypoprepia inculta & ABLCW244-10 \\
\hline Hypoprepia inculta & ABLCW245-10 \\
\hline Hypoprepia inculta & RDNME352-07 \\
\hline Hypoprepia inculta & MF923496.1 \\
\hline Hypoprepia inculta 3573 & MH337833 \\
\hline Hypoprepia inculta 3574 & MH337841 \\
\hline Hypoprepia inculta & ABLCW071-10 \\
\hline Hypoprepia inculta & ABLCW056-10 \\
\hline Hypoprepia inculta & ABLCW055-10 \\
\hline Hypoprepia lampyroides sp. n. 3566 & MH337834 \\
\hline Hypoprepia lampyroides sp. n. 3567 & MH337835 \\
\hline Hypoprepia lampyroides sp. n. 3568 & MH337836 \\
\hline Hypoprepia lampyroides sp. n. 3569 & MH337837 \\
\hline Hypoprepia lampyroides sp. n. 3570 & MH337838 \\
\hline Hypoprepia miniata & BBLOB1474-11 \\
\hline Hypoprepia miniata & LBCC462-05 \\
\hline Hypoprepia miniata & LBCC769-05 \\
\hline Hypoprepia miniata & LGSMB301-05 \\
\hline Hypoprepia miniata & LGSMB302-05 \\
\hline Hypoprepia miniata & LOFLB682-06 \\
\hline Hypoprepia miniata & LOFLC311-06 \\
\hline Hypoprepia sp. & KT706007.1 \\
\hline
\end{tabular}

heuristic searches were conducted using RAxML 8.0.9 (Stamatakis 2014) under the GTR+gamma model of evolution on CIPRES Science Gateway portal (Miller et al. 2010). 500 search replicates were conducted to find the maximum likelihood tree.

We identified the closest relatives of Hypoprepia in the resulting maximum likelihood tree, selected these as our outgroup taxa, and re-ran the ML heuristic searches (as 
described above) on the smaller matrix of 73 taxa. Clade support was conducted using rapid bootstrapping with a subsequent ML search and letting RAxML halt bootstrapping automatically (using MRE-based bootstopping criterion).

\section{Taxonomic treatment}

Genitalic preparations were made following the methods of Jaeger (2017) by staff at the CNC. Genitalia were slide-mounted using Euparal and photographed with a Leica DFC450 camera, Leica Application Suite 4.8 with a Leica M205C stereo microscope, and processed in Adobe Photoshop. Photographs of the pinned adult male and female paratypes were made using Visionary Digital Imaging System with a Canon EOS 7D digital camera and Canon MP-E65mm f/2.8 1-5× lens. Multiple images were combined using Zerene Stacker version 1.04.

Repository abbreviations are as follows:

CNC Canadian National Collection of Insects, Arachnids and Nematodes, Ottawa, ON

USNM National Museum of Natural History (formerly United States National Museum), Washington, DC

UAIC University of Arizona Insect Collection, Tucson, AZ

UNAM Universidad Nacional Autonoma de Mexico, Mexico, DF

DEBC Don E. Bowman Collection, Golden, Colorado

JDPC John D. Palting Collection, Tucson, AZ

RBNC Ray B. Nagle Collection, Tucson, AZ

\section{Results and discussion}

\section{Phylogenetic analysis}

Our molecular phylogenetic analyses reveal strong support for the monophyly of $H y$ poprepia and a close relationship between $H$. inculta and $H$. lampyroides (Figure 15). It is noteworthy that $H$. lampyroides is recovered as a single well-supported clade. However, recognizing this clade as a new species renders $H$. inculta paraphyletic in the COI gene tree. Focusing on gene tree topology alone, one might decide not to recognize $H$. lampyroides as a new species, but rather view it as a unique population of $H$. inculta. However, we contend that these are two valid species since specimens of both occur in strict sympatry at the Rose Peak locality and they are easy to distinguish morphologically by size, wing color, antennal structure, as well as the form of both male and female genitalia. We predict that the 657 base pair fragment of COI does not contain enough phylogenetic information to infer the Hypoprepia species tree with accuracy. This is a common result of phylogenetic analyses of the COI barcoding region within some 
Lepidoptera (Beltran et al. 2002, Wiemers and Fiedler 2007) and within noctuoids in particular (Schmidt and Sperling 2008, Zahiri et al. 2017). The lack of reciprocal monophyly among species in the tree could also result from ongoing hybridization events resulting in mtDNA introgression, and/or incomplete lineage sorting (Funk and Omland 2003).

The phylogeny also suggests that Hypoprepia is in need of further revisionary work, particularly with respect to species boundaries between $H$. miniata and $H$. cadaverosa. These fully allopatric species ( $H$. miniata common in the eastern US and $H$. cadaverosa common in the western US) look quite different from one another. Even so, several authors have suggested that they should be synonymized (Zahiri et al. 2017, Powell and Opler 2009). Given this and that both nominate forms are polyphyletic in our tree, it seems likely that these forms represent regional variation in the same species. Future investigations comparing their anatomy and phylogenetic analysis of additional genes, particularly nuclear genes, will help resolve this taxonomic question.

\section{Taxonomic treatment}

Hypoprepia lampyroides Palting \& Ferguson, sp. n. http://zoobank.org/746F6BFE-47B9-4E47-832B-F75A954A75C2 Figs $1-5,8-10,13-14,18-19$

Type material. Holotype $\widehat{\partial}$. Arizona:, [Apache Co.], White Mountains, Greer, 8,200 ft., 4-5 July 1988, R.H. Leuschner [USNM]. Paratypes $32 \widehat{\jmath} 3$ ㅇ. Arizona: Santa Cruz Co., 8.5 mi. SE of Patagonia, Harshaw Canyon, 4,850 ft., 24 July 1998, D.E. Bowman, 1 ㅇ [DEBC]; 29 2 을 Greenlee Co., Blue Ridge Primitive Wilderness, US Hwy 191 , vicinity of Rose Peak, $33^{\circ} 26^{\prime} \mathrm{N} 109^{\circ} 22^{\prime} \mathrm{W}, 8084 \mathrm{ft}$., 19 June 2017 [specimens dis-

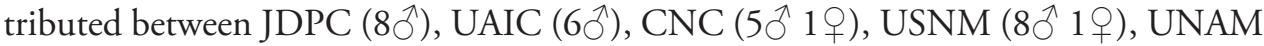

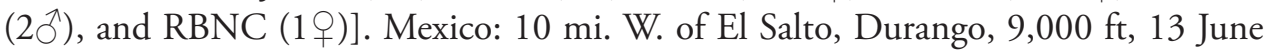

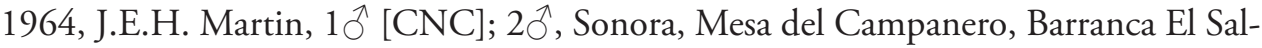
to, elevation 6561', Municipio de Yecora, , 2 July 2013, J. Palting [ JDPC, UNAM].

Etymology. The specific epithet lampyroides means "like Lampyra" referring to this species' remarkable mimicry of a sympatric lampyrid beetle species, as discussed below.

Diagnosis. Hypoprepia lampyroides (Figs $1-5$ ) occurs sympatrically with $H$. inculta (Figure 6) and is easily distinguishable externally by its larger size; unmarked blackish forewings; brighter more extensively pink hindwings; somewhat different palpi; and different male antennae that more nearly resemble those of $H$. cadaverosa. The antenna differs structurally from that of $H$. inculta (Figure 7), which exhibit squarish, closely set segments (flagellomeres) with little space between them. The laminae of the antennal segments of $H$. lampyroides (Figure 8) are conspicuously raised, tapered, and appear farther apart when viewed laterally. The antenna of $H$. lampyroides is more like that of $H$. cadaverosa, a species that it does not otherwise resemble. 


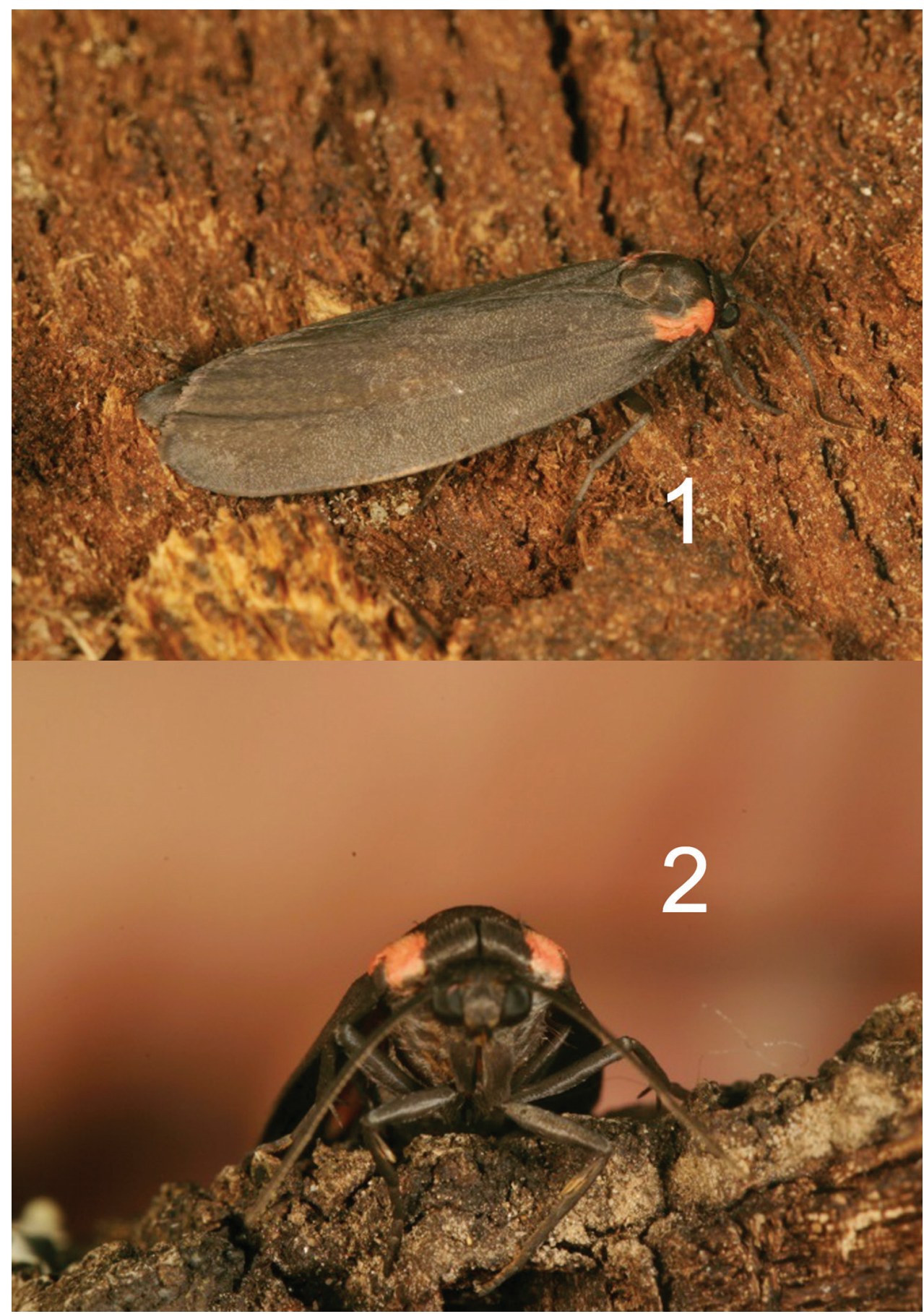

Figures I-2. Two views of living male Hypoprepia lampyroides. 


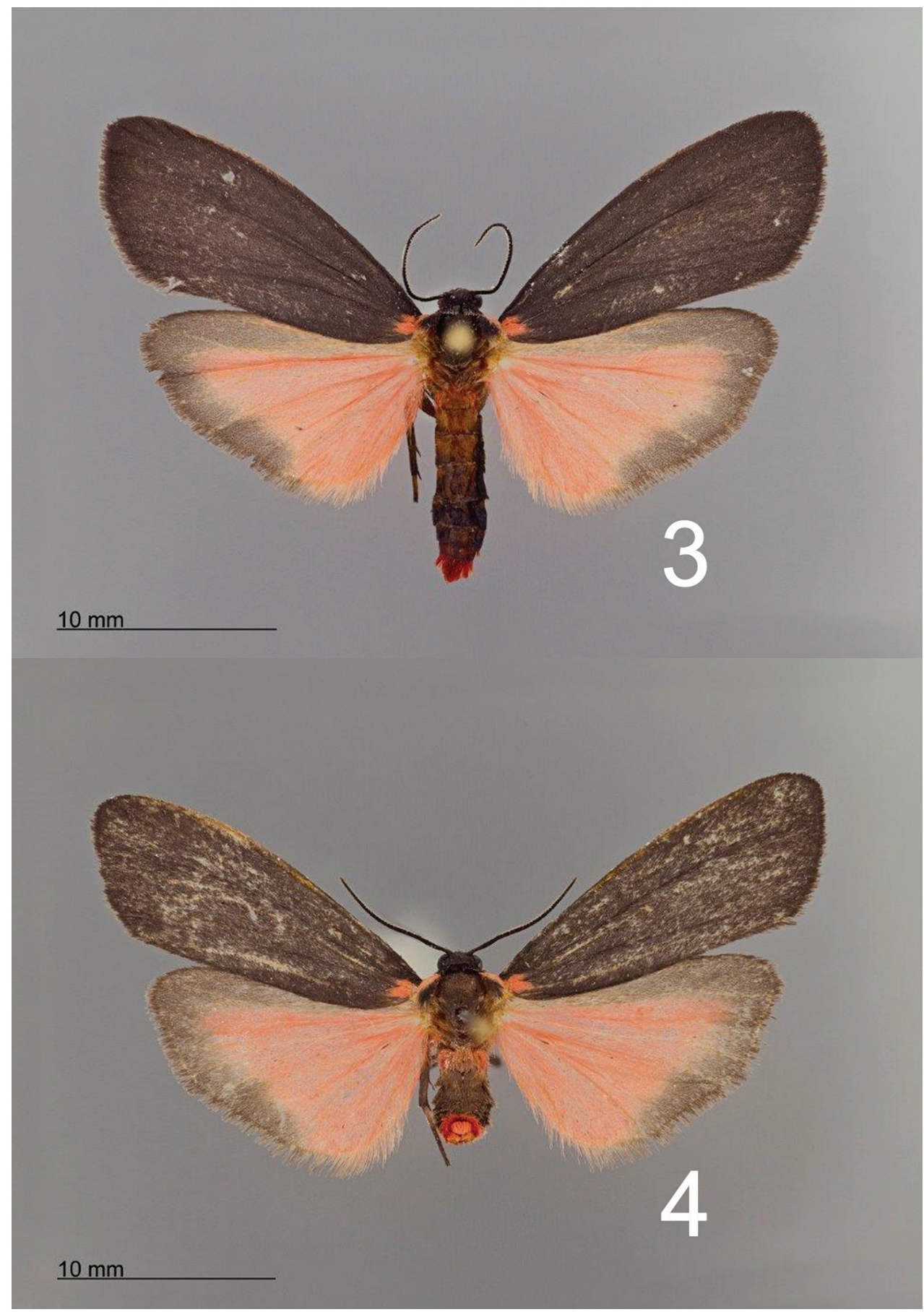

Figures 3-4. Adults of Hypoprepia lampyroides. 3 male and $\mathbf{4}$ female. 


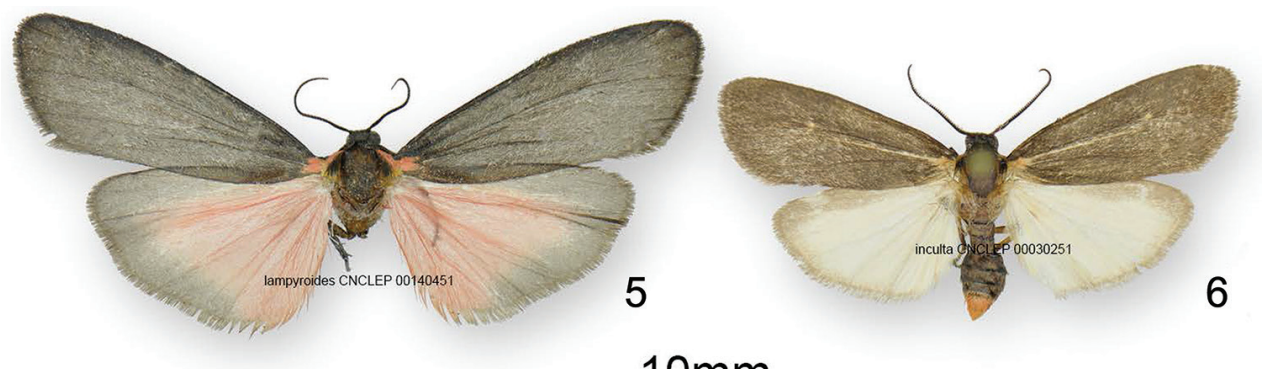

\section{$10 \mathrm{~mm}$}

Figures 5-6. Adult male $\mathbf{5}$ Hypoprepia lampyroides and $\mathbf{6}$ Hypoprepia inculta.

Internally, the male $H$. lampyroides (Figs 9-10) differs from $H$. inculta (Figs 11-12) in the form of the spinose cornutus on the dorsal vesica chamber, which is apically elongated in $H$. lampyroides versus sawblade-like in $H$. inculta. Hypoprepia lampyroides males always have three well-developed spinose cornuti (Figure 10), whereas the left ventrolateral cornutus (adjacent to the ductus) is often missing or reduced in $H$. inculta (Figure 12). The shape of the valve and tegumen is stouter and less elongate than in $H$. inculta. In females, the corpus bursae is globose (Figure 13) versus irregularly elongate in $H$. inculta (Figure 14), with four instead of three signa, the right-ventral signa possessing smaller spines than the corresponding right-ventral signa in $H$. inculta.

Description. Sexes similar externally (Figs 3-4), but females with pink area on dorsal hindwing not quite as extensive, and with boundary between pink part and dark outer border more diffuse. Head. Vestiture of frons and vertex dark grey; labial palpus dark grey, upturned, slightly larger and longer than that of $H$. inculta, terminal $\left(3^{\text {rd }}\right)$ segment $1.25 \times$ longer than $2^{\text {nd }}$; eye large, protuberant, more clearly exceeding a half sphere than those of the other Hypoprepia species; male antenna blackish, laminate, densely clothed with short setae beneath and with a few longer setae protruding sublaterally along the sides; female antenna simple, flagelliform.

Thorax. Dark brown or dark gray except for the tegula, which is mostly bright pink, matching basal spot of forewing; patagium blackish; legs entirely blackish or dark gray.

Abdomen. Vestiture gray, flushed with pink basally and terminally, ventrum entirely blackish or dark gray, except for some pink scales at distal end ( $H$. inculta also may have a pink-tipped abdomen); ventral sternite A8 of males with reinforced, sclerotized rim-like anterior margin, but no pockets, coremata or androconial setae are visible on segments A7-A8. In females, pleurite of A7 with membranous but thick pockets, appearing somewhat rugose and more heavily sclerotized than surrounding integument. Forewing. Uniformly dark brown to charcoal gray, appearing blackish, unmarked except for a pink spot at base next to thorax, and lacking the pale streak on basal half of cubital vein seen in many $H$. inculta; male forewing length $17-20 \mathrm{~mm}$, mean 17.5 $\mathrm{mm}(n=6)$; female average forewing length $15.8 \mathrm{~mm}(n=2)$ (usually $12-15 \mathrm{~mm}$ for both sexes of $H$. inculta). Hindwing. Hindwing pink, with a uniform, dark-gray costal and outer margin, ending just before anal angle; fringes gray to dark brown; ventrum 


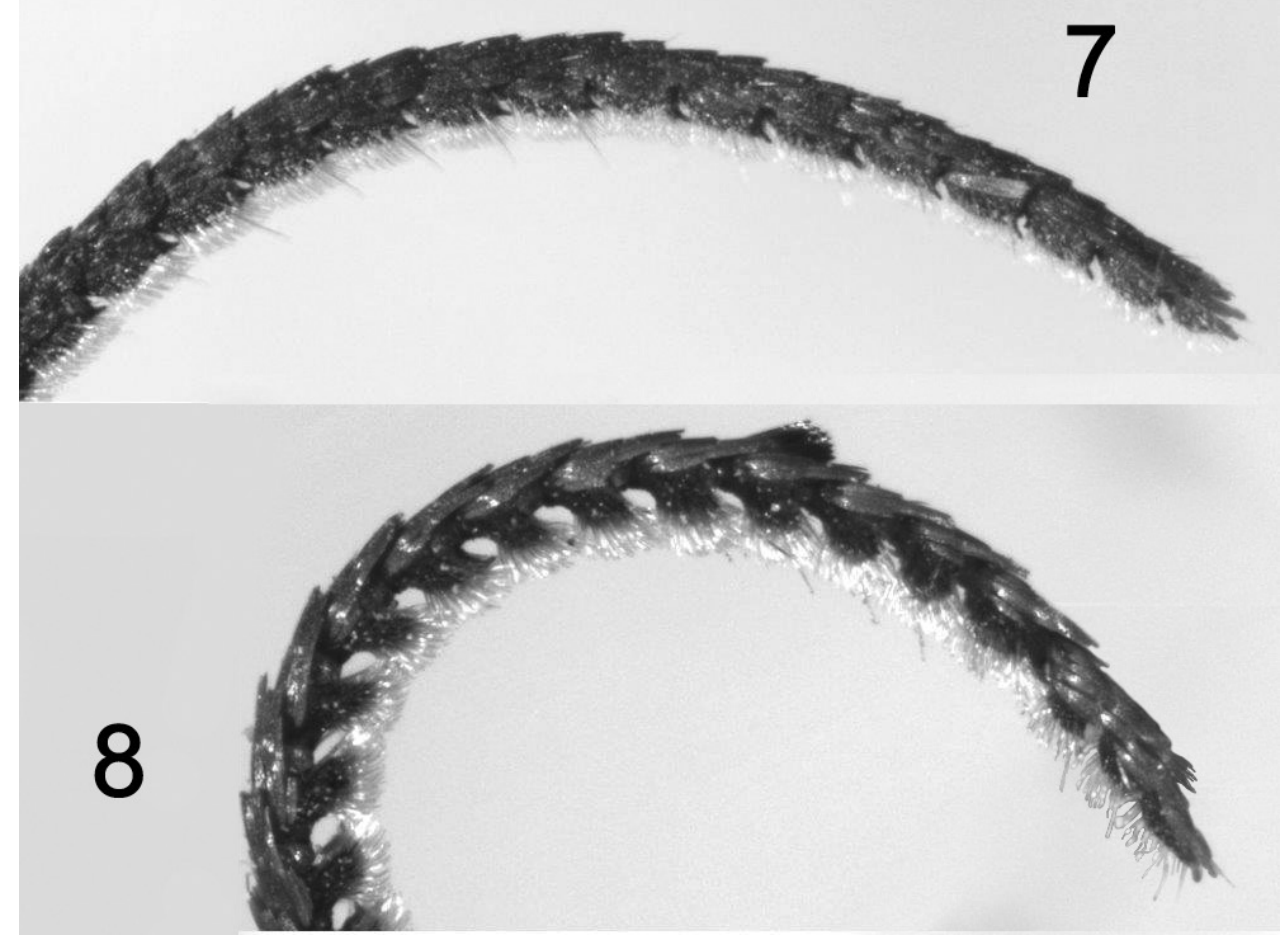

Figures 7-8. Lateral view of male antennae: 7 Hypoprepia inculta 8 Hypoprepia lampyroides

of both wings similar to dorsum but slightly paler, and with more diffuse boundaries between pink and gray areas. Male genitalia (Figs 9-10) Generally similar to those of $H$. inculta; uncus cylindrical, flattened slightly laterally, oval in cross section, 8.8 $\times$ longer than wide; apex formed by slightly ventrally-curved, fine spine; basal two thirds with sparse, latero-basally directed setae; tegumen well-defined, rounded quadrate and dorsoventrally flattened with a slight constriction at juncture with vinculum; dorsal surface convex and bubble-like on either side of midline, densely covered in setal sockets distally; valve without clasper or process, slightly constricted basally, distal half rounded triangular, apex a rounded point, with short, broad somewhat spine-like setae along distal third of costal margin; sacculus not differentiated from remainder of valve, with a slight sub-basal, setose bulge; juxta indistinct, forming a dorsally emarginate rounded-rectangular transverse plate, approximately $4 \times$ wider than long; phallus a straight, simple cylinder, $2.5 \times$ longer than wide, coecum lacking; vesica consisting of three adjoining, globose chambers, the phallus appearing more or less as a tripartite club when vesica expanded; ventral chamber adjacent to ductus ejaculatorius, with additional lobe-like diverticulum, and with a spinose crest-like patch apically; laterodorsal chambers also with spinose crests. Female genitalia. (Figure 13) Papillae anales broadly diamond-shaped, sparsely setose; anterior and posterior apophysis relatively short, approximately equal in length to width of papillae; postvaginal aree with tri- 


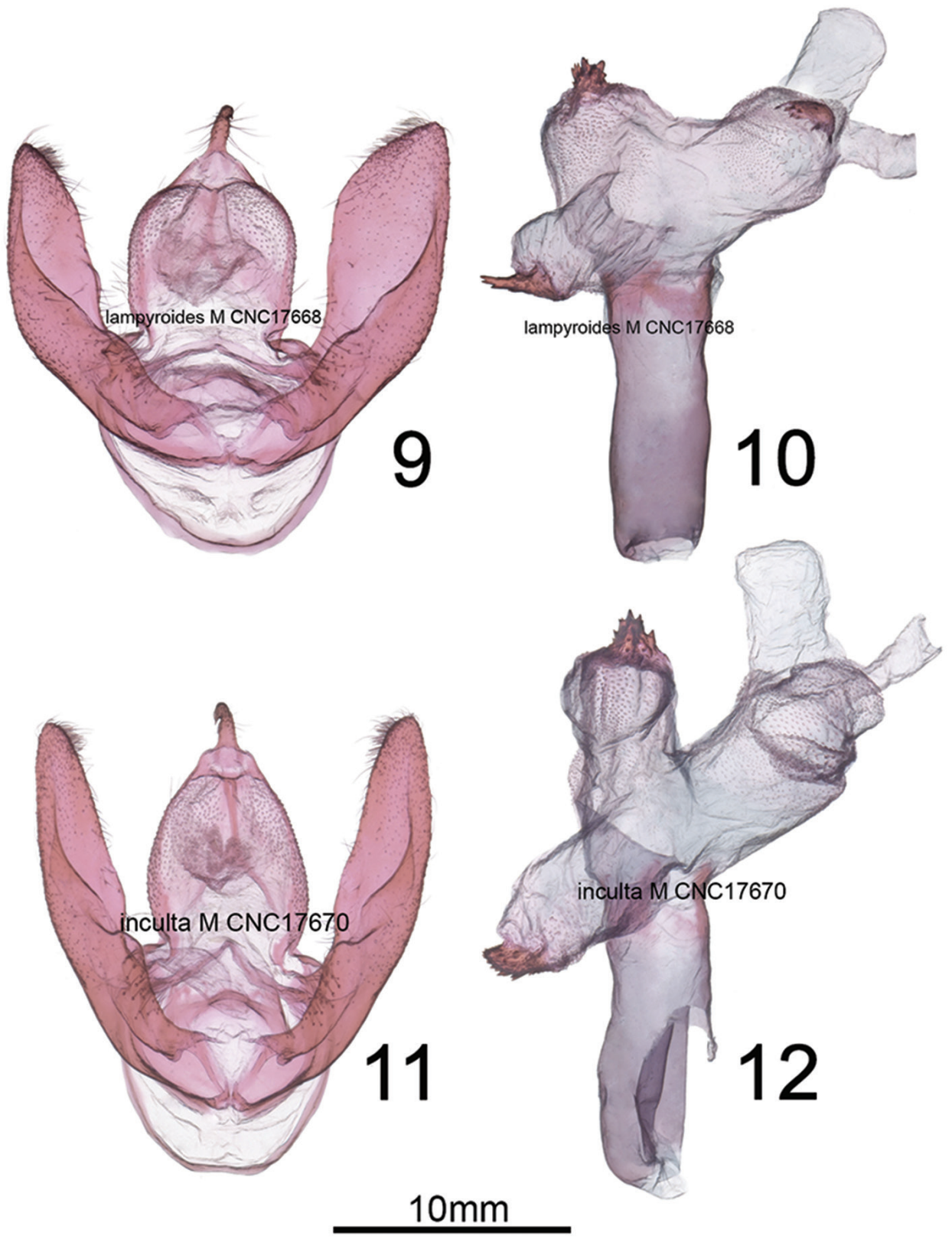

Figures 9-I 2. 9-I0 Male genitalia of Hypoprepia lampyroides I I-I 2 Male genitalia of Hypoprepia inculta.

angular scerlotization; ductus bursae short and broad, $1.5 \times$ wider than long, highly flattened dorsoventrally and recurved ventrally; corpus bursae relatively small and globose, diameter 1.5-2 $\times$ width of ductus; signa consisting of two pairs of spinose straps, situated laterally near junction of ductus; cervix bursae situated right caudo-laterally and recurving left across ventral side of ductus. 

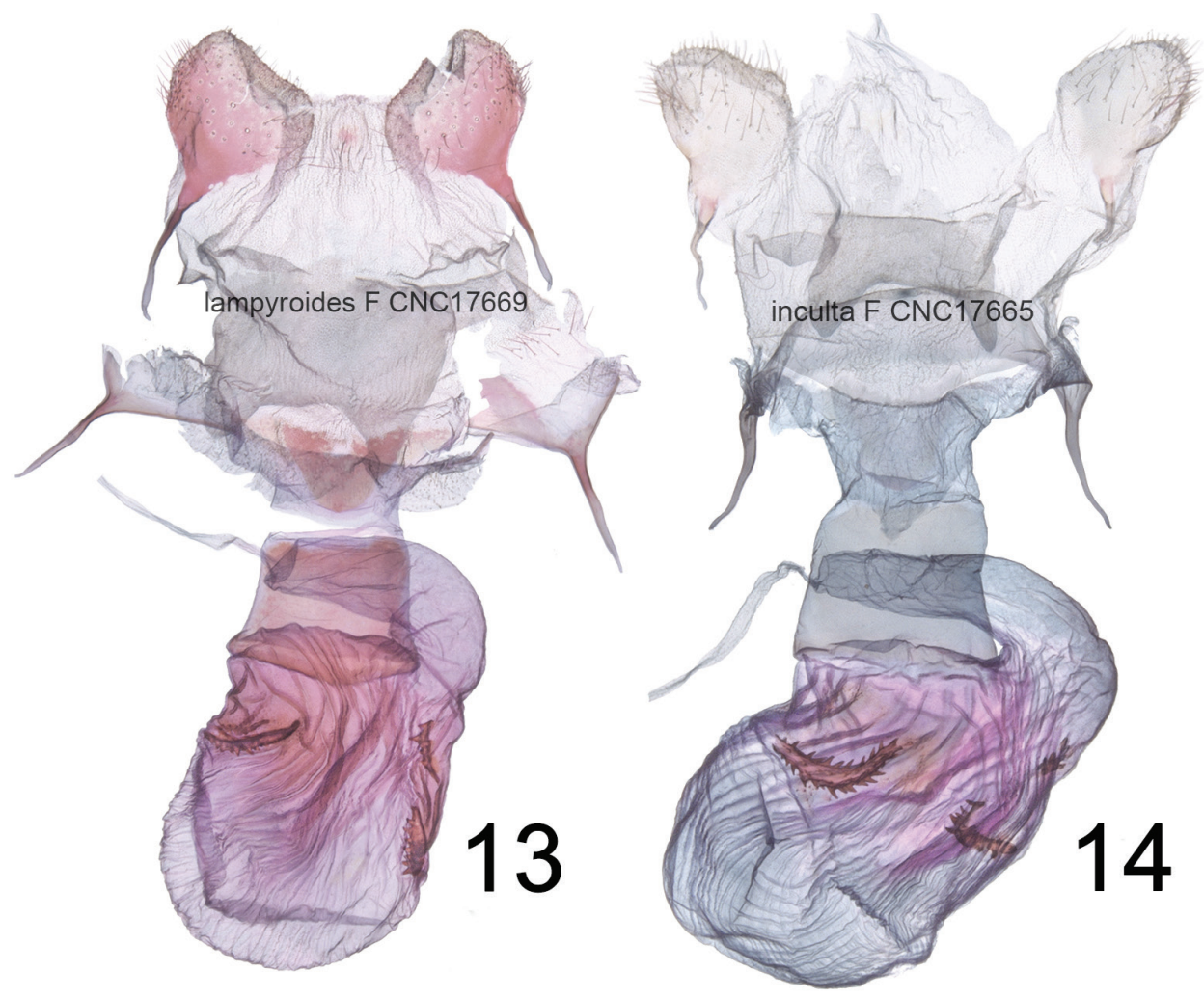

$10 \mathrm{~mm}$

Figures 13-14. Female genitalia of I3 Hypoprepia inculta and I4 Hypoprepia lampyroides.

Biology and distribution. The brown eggs of $H$. lampyroides (Figure 16) were laid in small clusters inside a vial containing a piece of paper, and under magnification exhibit the "hammered copper" surface texture typical of lithosiine ova. These hatched after 14 days, the larvae being light yellowish initially then darkening as they fed. The larval stages are basically dark brown and unmarked throughout their development. Like other Hypoprepia (and other members of the subtribe Cisthenini) the larvae lack true verrucae (Bendib and Minet 1999) and instead have structures technically known as panniculae (Stehr 1987) with just one or two, stiff, black setae emerging from each (Figs 17-19). The larva is similar to $H$. inculta, which is also predominantly brown with black setae, while $H$. cadaverosa, reared by JDP at the same time as $H$. lampyroides, are marked with bright yellow bands (Figure 20). The larval mandible, dissected (Figure 21), shows the enlarged molar region found in other lithosiines. This feature has been suggested as a synapomorphy for the Lithosiini (Bendib and Minet 1999) and is believed to be related to their lichen diet. The larvae fed successfully on a mixed population of lichens obtained by shaving bark off oak trees, and developed through six instars into a caterpillar large enough to pupate. Unfortunately, lab conditions failed to yield a successful pupation, 


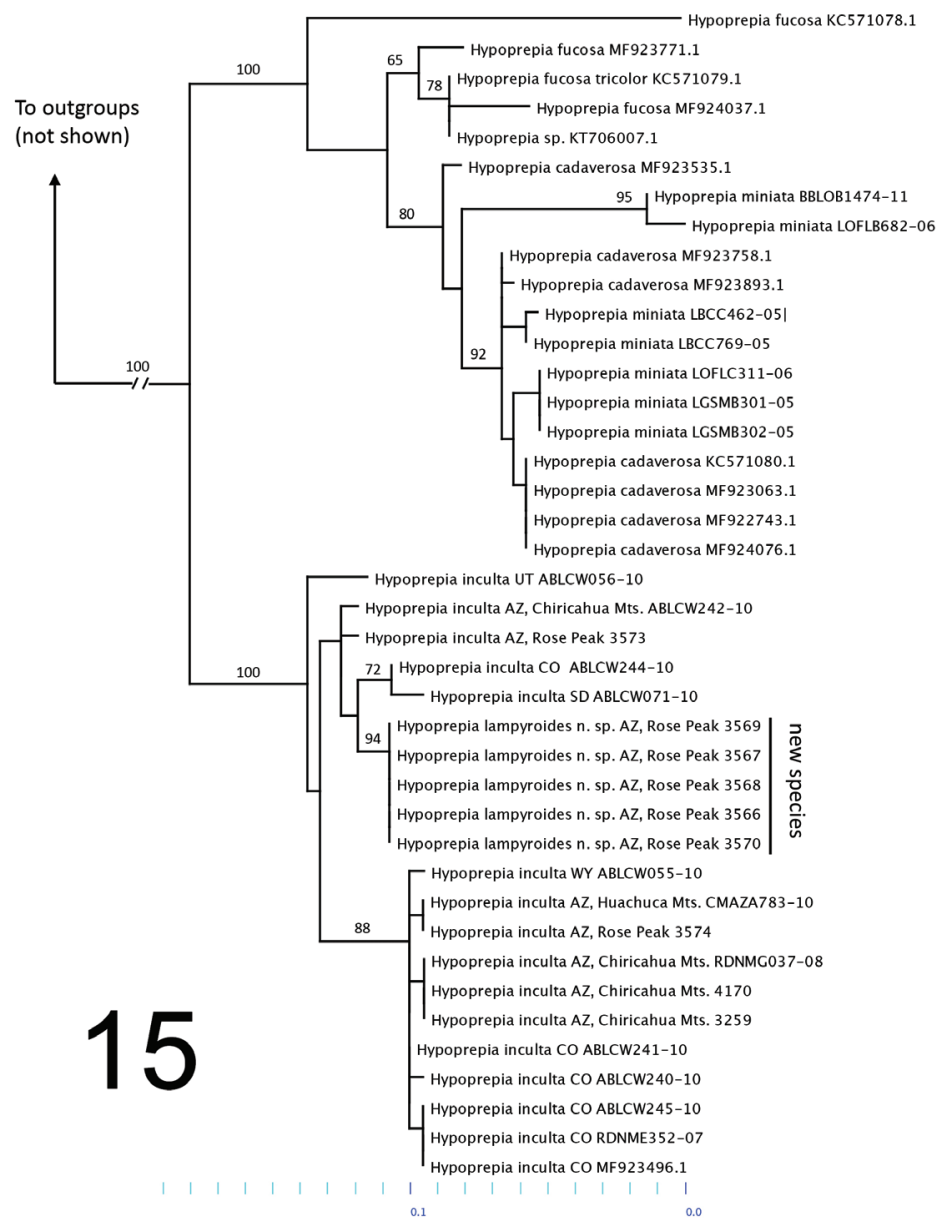

Figure I5. Maximum-likelihood tree of Hypoprepia species based on COI. Bootstrap values are reported on the branches subtending nodes with a support value greater than 50 .
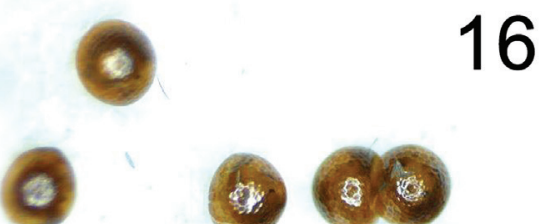

\section{30}

Figure 16. Eggs of Hypoprepia lampyroides, approximately 20×. 

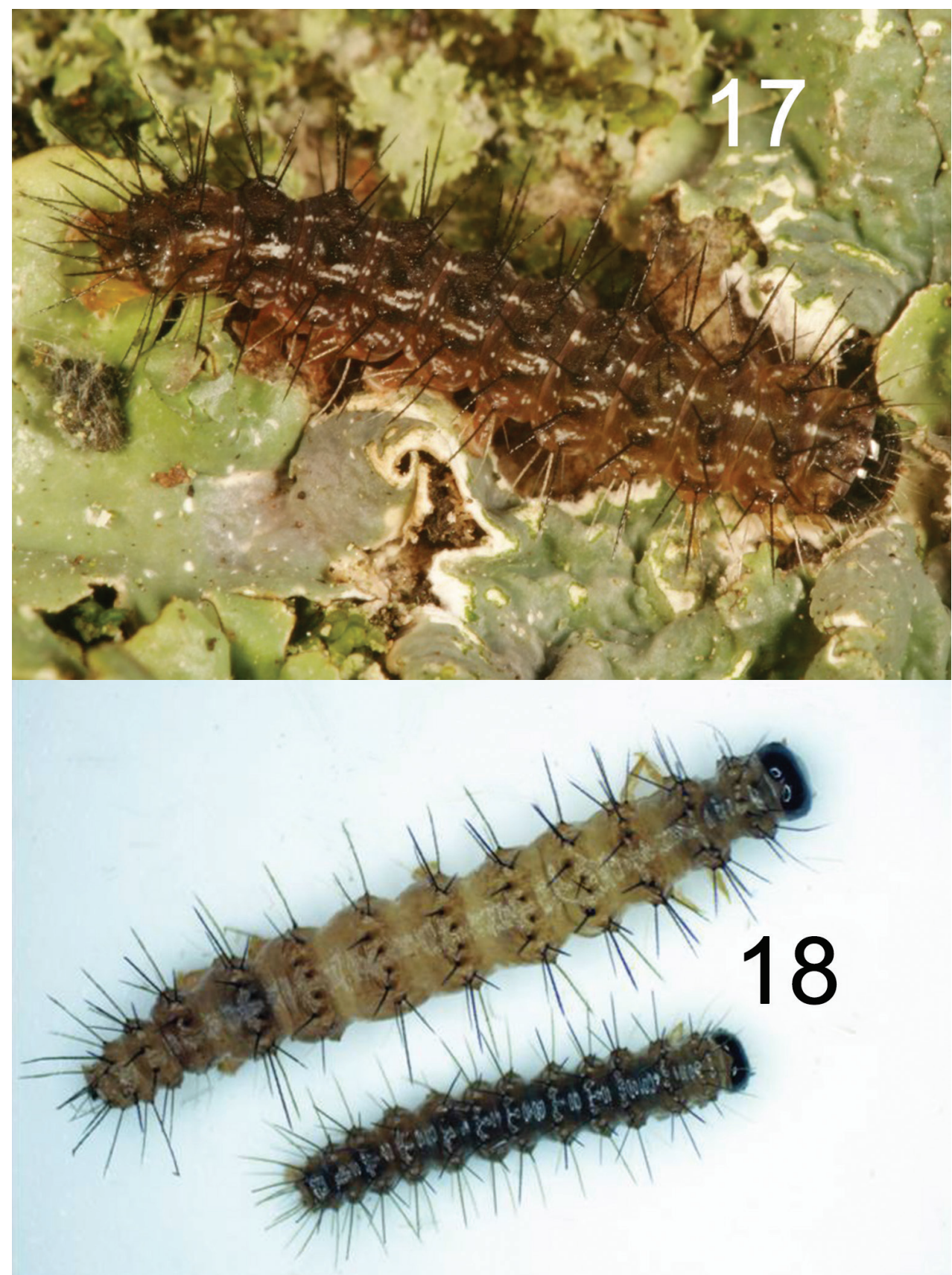

Figures 17-18. Larvae of Hypoprepia lampyroides. 17 Living last instar larva and 18 Penultimate instar larvae, preserved. 

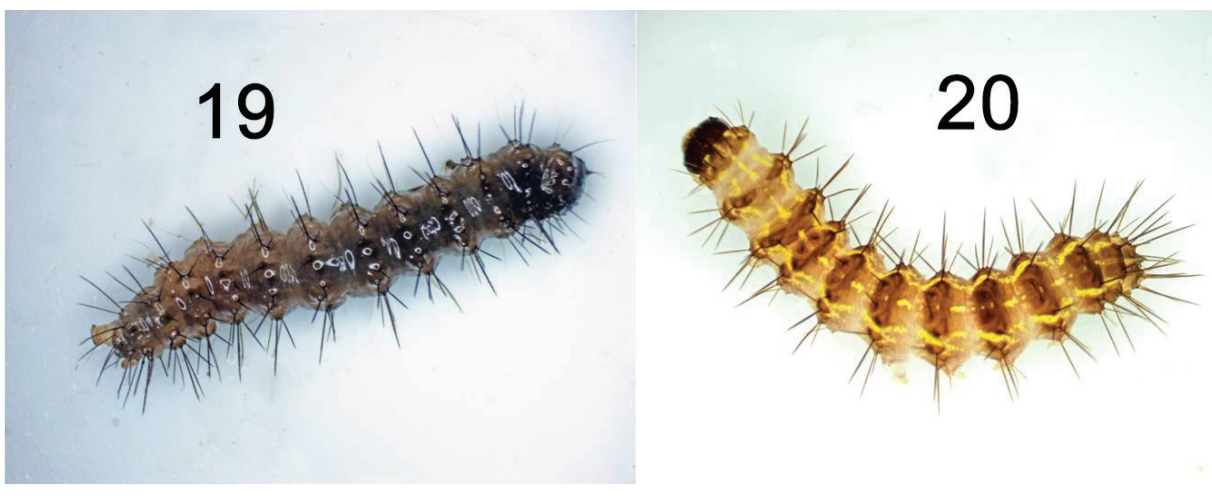

Figures 19-20. Last instar larvae of 19 Hypoprepia lampyroides and 20 Hypoprepia cadaverosa, preserved.

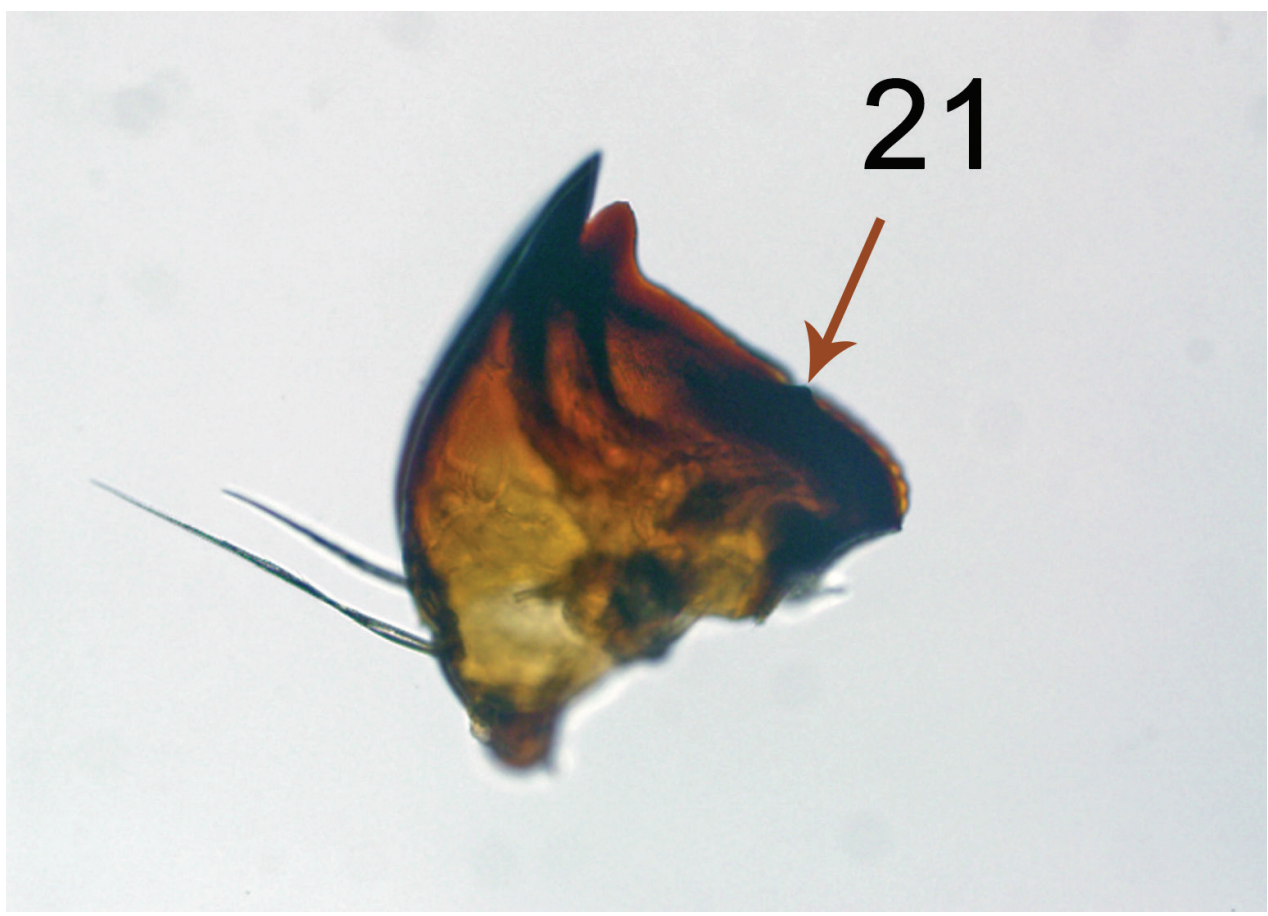

Figure 2I. Mandible of last instar Hypoprepia lampyroides, approximately $20 \times$.

and the larvae eventually died. It is likely that $H$. lampyroides over-winter as a fully mature larva, pupating in the spring and emerging in early summer.

The striking resemblance of this moth at rest (Figs 1-2) to a common southwest species of firefly, Ellychnia corrusca Linnaeus, 1767 (Coleoptera: Lampyridae) (Figure 23), points to them being part of a mimicry ring, which also includes another common montane beetle, Discodon bipunctatum Schaeffer, 1908 (Coleoptera: Cantharidae) (Figure 22). Ellychnia corrusca was common during the day in the Rose Peak area, and the 


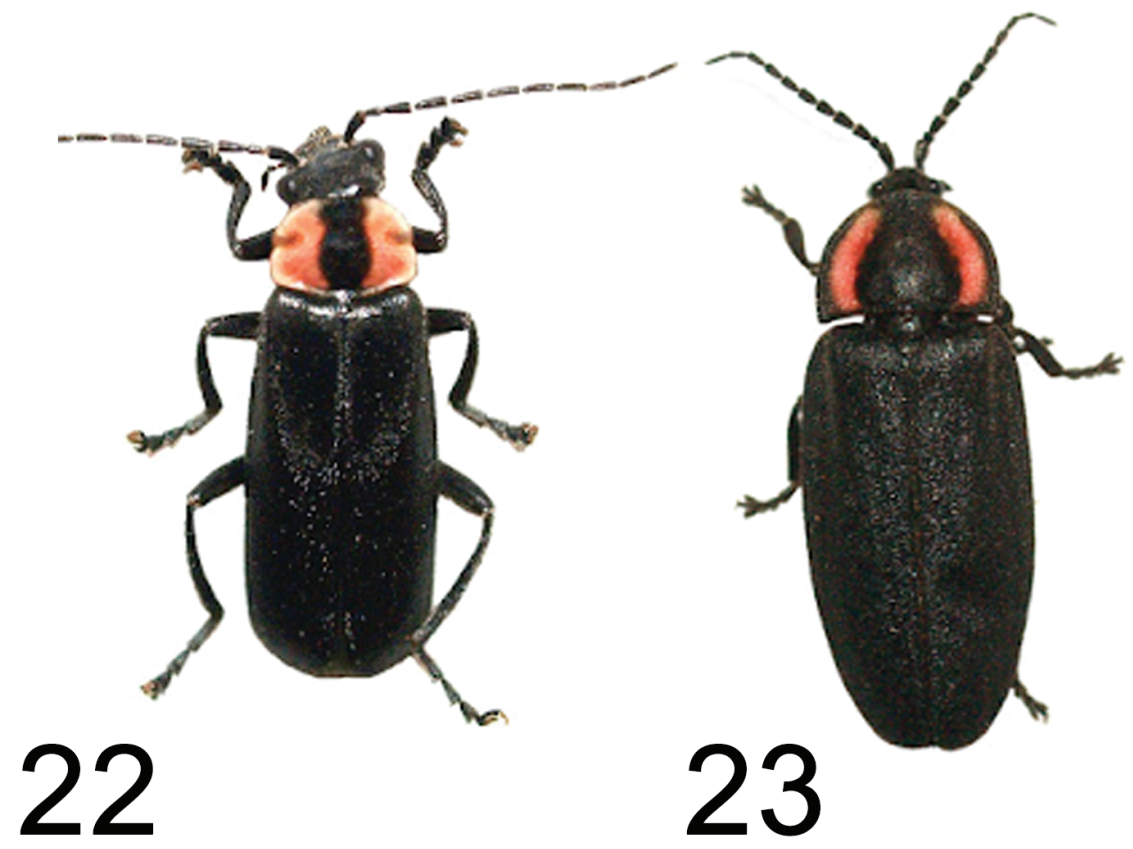

Figures 22-23. Mullerian mimicry with Coleoptera. 22 Discodon bipunctatum (Cantharidae) 23 Ellychnia corrusca (Lampyridae).

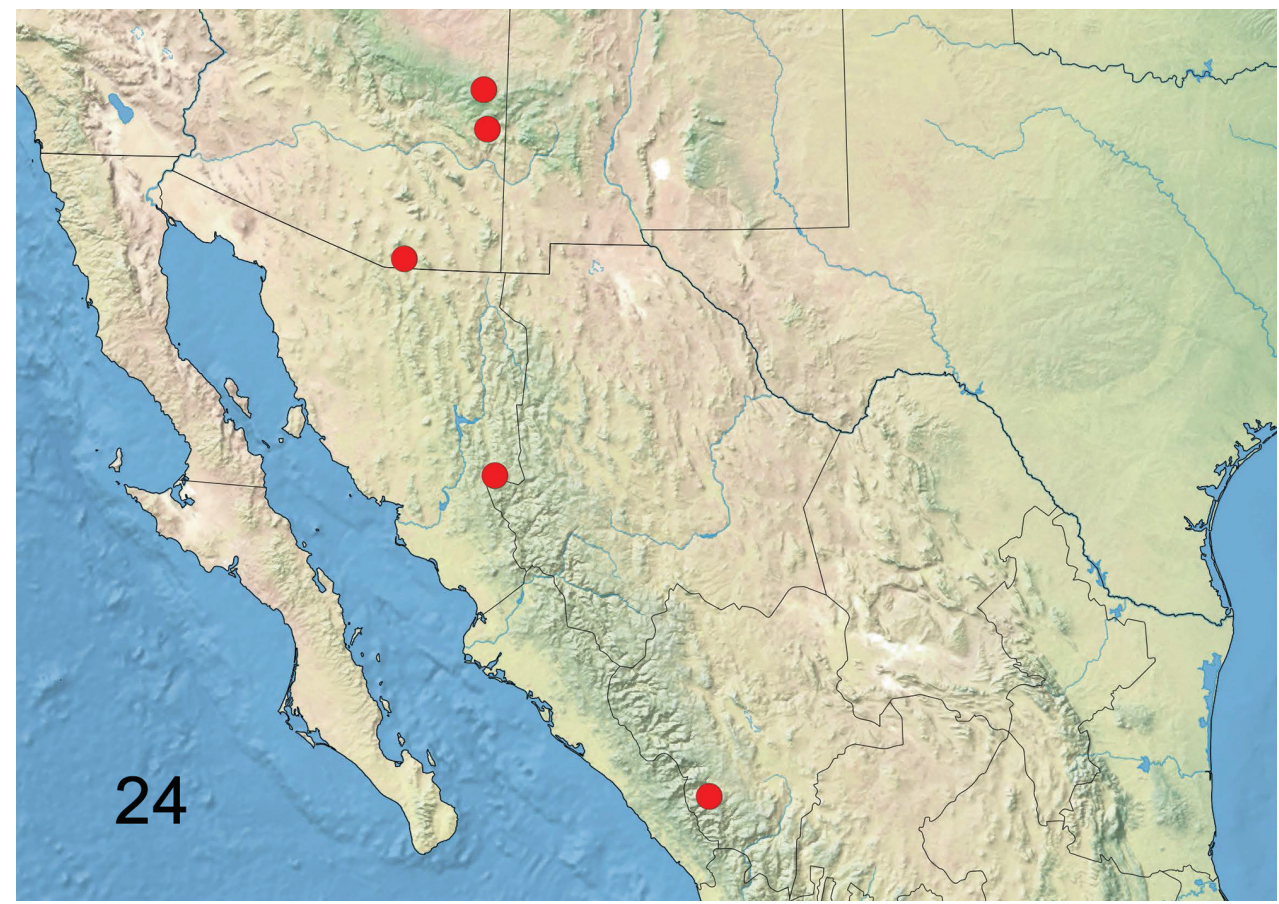

Figure 24. Range map of Hypoprepia lampyroides. 
bright pink markings on its pronotal region closely match the pink markings at the base of the forewing in $H$. lampyroides, likely affording the resting moths protection should a bird or other predator come upon them. Lampyrids are known to be chemically protected and distasteful to birds, but unlike most familiar nocturnal fireflies, Ellychnia lacks an abdominal light and is primarily diurnal. Research on sequestration of lichen polyphenolic compounds by other lithosiine arctiids (Hesbacher et al. 1995, Conner 2009, Scott et al. 2014) suggests that $H$. lampyroides itself has some chemical protection, thus the mimicry between these organisms is likely Mullerian. H. inculta is also likely part of this mimicry ring, although with its smaller size, dull pink markings, and grey wing color, it is a much less dramatic match to Ellychnia than H. lampyroides.

Hypoprepia lampyroides is known from over 30 specimens collected in Arizona, two specimens from Yecora, Sonora, Mexico and one from Durango, Mexico (Figure 24).

Remarks. When examining the nearest relatives of $H$. lampyroides, Ferguson found that $H$. inculta from the southwestern United States is indistinguishable from the type material of $H$. muelleri Dyar, described from the vicinity of Mexico City, H. muelleri tends to have darker, more grayish hindwings, although in some $H$. inculta from Arizona they are equally grayish. Such a difference by itself is hardly significant. Unfortunately, fresh collected material of $H$. muelleri was not available for molecular analysis, but Ferguson's conclusion based on his examination of the type material results in the following taxonomic change: Hypoprepia muelleri Dyar, = Hypoprepia inculta Henry Edwards, syn. n. This extends the known range of $H$. inculta from as far north as Utah to the vicinity of Mexico City. H. muelleri had previously been the only member of the genus found exclusively in Mexico.

Ferguson found the Durango, Mexico specimen of $H$. lampyroides among unidentified arctiids from the Canadian National Collection. The region of El Salto, Durango, where it was collected, is mesic, conifer-dominated forest similar to that around Greer, Rose Peak, and Yecora, Sonora. The Harshaw specimen, a female, was collected by Don Bowman of Golden, Colorado and sent to Ferguson for identification. The Harshaw region is rather dry mid-elevation oak woodland/mesquite grassland, very unlike where all the other specimens of this moth have been collected.

\section{Acknowledgments}

JDP is greatly indebted to Chris Schmidt for sending him Ferguson's unfinished manuscript on this moth, for extensive help with the genitalic descriptions and for many helpful suggestions to improve the paper; to Christi Jaeger for the genitalic dissections and photos; to Ray Nagle for many years of mentoring and friendship, reviewing the manuscript and for photographing the adult and larvae of $H$. lampyroides; to Charles "Chip" Hedgcock for the exquisite portraits of the new taxa and to Margarethe Brummermann for allowing the use of her combined image of Ellychnia corrusca and Discodon bipunctatum to illustrate the similarity in color pattern between these taxa and $H$. lampyroides. This work is in partial fulfillment of JDP's Doctorate of Philosophy degree 
in the Graduate Interdisciplinary Program in Entomology and Insect Science at the University of Arizona and is the product of the Arizona Sky Island Arthropod Project (ASAP) based in WM's laboratory. JDP would like to thank extend special thanks to WM for her guidance in writing this manuscript and for her support and mentoring in the molecular systematics of lithosiines.

\section{References}

Beltran M, Jiggins CD, Bull V, Linares M, Mallet J, Owen McMillan W, Bermingham E (2002) Phylogenetic discordance at the species boundary: comparative gene genealogies among rapidly radiating Heliconius butterflies. Molecular Biology and Evolution 19(12): 2176-2190. https://doi.org/10.1093/oxfordjournals.molbev.a004042

Bendib A, Minet J (1999) Lithosiinae main lineages. Annales de Societe Entomologique de France 35(3/4): 241-263.

Conner WL [Ed.] (2009) Tiger Moths and Woolly Bears: Behavior, Ecology and Evolution of the Arctiidae. Oxford University Press.

Funk DJ, Omland KE (2003) Species-level paraphyly and polyphyly: frequency, causes, and consequences, with insights from animal mitochondrial DNA. Annual Review of Ecology and Evolutionary Systematics.34: 397-423. https://doi.org/10.1146/annurev.ecolsys.34.011802.132421

Green P (1999) Phrap. Version 0.990329 http://phrap.org

Green P, Ewing B (2002) Phred. Version 0.020425c. http://phrap.org

Hebert PDN, Cywinska A, Ball SL, deWaard JR (2003) Biological identifications through DNA barcodes. Proceedings of the Royal Society B 270(1512). https://doi.org/10.1098/ rspb.2002.2218

Hesbacher S, Giez I, Embacher G, Fiedler K, Max W, Trawoger A, Turk R, Lange OL, Proksch $\mathrm{P}$ (1995) Sequestration of lichen compounds by lichen-feeding members of the Arctiidae (Lepidoptera). Journal of Chemical Ecology 21(12): 2079-2089. https://doi.org/10.1007/ BF02033864

Jaeger CM (2017) Phylogeny of Tortricidae (Lepidoptera): A morphological approach with enhanced whole mount staining techniques. MSc Thesis, Mississippi State University, Strakville, MS, 117 pp.

Katoh K, Standley DM (2013) MAFFT Multiple Sequence Alignment Software Version 7: Improvement in Performance and Usability. Molecular Biolology and Evolution 30(4): 772-780. https://doi.org/10.1093/molbev/mst010

Maddison DR, Maddison WP (2017) Chromaseq: a Mesquite package for analyzing sequence chromatograms. Version 1.3. http://mesquiteproject.org/packages/chromaseq

Maddison WP, Maddison DR (2018) Mesquite: a modular system for evolutionary analysis. Version 3.40. http://mesquiteproject.org

Miller MA, Pfeiffer W, Schwartz T (2010) Creating the CIPRES Science Gateway for inference of large phylogenetic trees. Proceedings of the Gateway Computing Environments Workshop (GCE). New Orleans, Louisiana, 1-8. https://doi.org/10.1109/GCE.2010.5676129 
Powell JA, Opler PA (2009) Moths of Western North America. University of California Press. Scott CH, Zaspel JM, Chialvo P, Weller SJ (2014) A preliminary molecular phylogenetic assessment of the lichen moths (Lepidoptera: Erebidae: Arctiinae: Lithosiini) with comments on palatability and chemical sequestration. Systematic Entomology 39: 286-303. https://doi. org/10.1111/syen.12047

Schmidt BC, Sperling FAH (2008) Widespread decoupling of mtDNA variation and species integrity in Grammia tiger moths (Lepidoptera: Noctuidae). Systematic Entomology 33(4): 613-634. https://doi.org/10.1111/j.1365-3113.2008.00433.x

Stamatakis A (2014) RAxML version 8: a tool for phylogenetic analysis and post analysis of large phylogenies. Bioinformatics 30: 1312-1313. https://doi.org/10.1093/bioinformatics/btu033

Stehr FW (1987) Immature Insects, vol. 1. Kendal V Hunt Publishing, Dubuque, Iowa, 754 pp. Warshall P (1995) The Madrean Sky Island Archipelago: A planetary overview. In: DeBano, LH, Ffolliot PF, Ortega-Rubio A, Gottfried G, Hamre RH, Edmister CB (Eds) Biodiversity and management of the Madrean Archipelago: The Sky Islands of Southwestern United States and Northwestern Mexico. 1994 Sept. 19-23; Tucson, AZ. Tech. Rep. RMGTR-264. Fort Collins, CO: US Department of Agriculture, Forest Service, Rocky Mountain Forest and Range Experimental Station.

Wiemers M, Fiedler K (2007) Does the DNA barcoding gap exist? - a case study in blue butterflies (Lepidoptera: Lycaenidae). Frontiers in Zoology 4(8). https://doi.org/10.1186/17429994-4-8

Zahiri R, Lafontaine JD, Schmidt BC, deWaard JR. Zakharov EV, Hebert PDN (2017) Probing planetary biodiversity with DNA barcodes: The Noctuoidea of North America. PLoS ONE 12(6): e0178548. https://doi.org/10.1371/journal.pone.0178548 